\title{
Evaluation of adequacy of a model of a marine diesel engine based upon empirical research
}

The article presents a mathematical model of a marine diesel engine developed for the needs of the research on the innovative method of evaluating technical condition of a marine engine. Basic assumptions of the method under development have also been included. The main focus has been directed on the evaluation of adequacy of a mathematical model of a marine diesel engine proposed in this article. In addition, measures of adequacy for the needs of the conducted research have also been presented. Finally, the article shows results from the conducted research followed by conclusions.

Key words: marine diesel engine, diagnostics, modelling

\section{Introduction}

Evaluation of technical condition of marine diesel engines driving electric power generators constitutes a vital issue in their operation. Certain number of marine diesel engines is operated following their technical condition strategy. These are mostly the engines of a high diagnostic susceptibility (provided by their manufacturers with indicator valves) [9] intended for the ships' propulsion. A separate group of these engines are used as auxiliary engines intended for driving synchronous electric power generators. These engines usually represent a low diagnostic susceptibility (they are not equipped with indicator valves). Such engines are operated following the strategy of the so-called hourly resources (a definite amount of time of reliable operation). The strategy provides periodical replacement of the engine component parts regardless of their actual technical condition. This implies necessity to put the engine out of service and often to replace elements still fit for use. High cost of maintenance to be performed and considerable amounts of labour raise necessity to seek non-invasive, parametric evaluation methods of technical condition of the said engines. One of the most popular methods is assessing the technical condition of engines is their indication [10, 11, 14]. Another popular methods is assessment of the technical condition of engines based on acceleration measurements are particularly popular [2, 3, 6, 20]. Optical studies using endoscopes to assess the surface condition of engine working spaces are also popular. Another method is the evaluation of technical condition of a marine diesel engine based on measurements of pressure in the exhaust outlet ducts [5, $8,15]$.One of them is a method developed for evaluation of technical condition of an engine used for driving synchronous electric power generators based on measurements of its phase-to-phase voltage.

The article presents a part of conducted research included an assessment of the adequacy of the developed mathematical model. The tests were conducted on an engine with high diagnostic susceptibility (SULZER type 6AL20/24 laboratory engine). They included an active experiment for the engine and model both. The tests were carried out for full range of rotational speeds of the engine crankshaft and torque load. In addition, tests were carried out for the full and partial condition of the engine (one of the engine cylin- ders was shut down). The research included measures of adequacy parameters measurable on a real object as well as those obtainable as a result of solving model equations. Additionally, a measure of adequacy was proposed taking into account the similarity of the indicator charts.

\section{Assumptions regarding the developed method}

This method is based upon the assumption that technical condition of a marine diesel engine driving a synchronous electric power generator produce direct impact on the shape of waveforms of the phase-to-phase voltage of the generator. During the tests it was observed that technical condition of an engine and its load with a torque (the course of the working process inside the cylinders) have a direct impact on fluctuations of the rotational speed of its crankshaft during its working process $[1,16]$. The fluctuations of the rotational speed of the engine crankshaft and those of the generator impeller (in case of a generating set driven by an diesel engine) are practically of the same nature. They modify the shapes of the waveform of the phase-to-phase voltage of the generator.

The course of the working process of an engine depends mainly on its technical condition and on its loading with a torque. This translates into the indicated pressure (Fig. 1) and by the same into the torque generated by the engine (Fig. 2). The shape of the waveform of the rotational speed of the engine crankshaft as a function of time depends on the torque and on the moments of inertia of the components of the engine performing reciprocating motion, rotating motion and a complex (both reciprocating and rotating) motion. As the inertia moments of the engine components are constant, the course of the angular velocity depends on the torque of the crankshaft (indicated pressure) (Fig. 3).

The forces generating the load of the engine with a torque cause the occurrence of pseudo-periodical deformations [4] of the shape of the torque waveform and variations of the rotational speed of the crankshaft as a function of the duration time equal to the multiplicity of the basic harmonic wave (resulting from the rotational motion of the crankshaft) and of the half-number of the engine cylinders (in case of a four-stroke engine). On the other hand, the forces generated by the disturbances of the waveform of the working process in one of the engine cylinders have a peri- 
od equal to a half of the basic harmonic wave resulting from the rotational motion of the engine crankshaft (in case of a four-stroke engine).

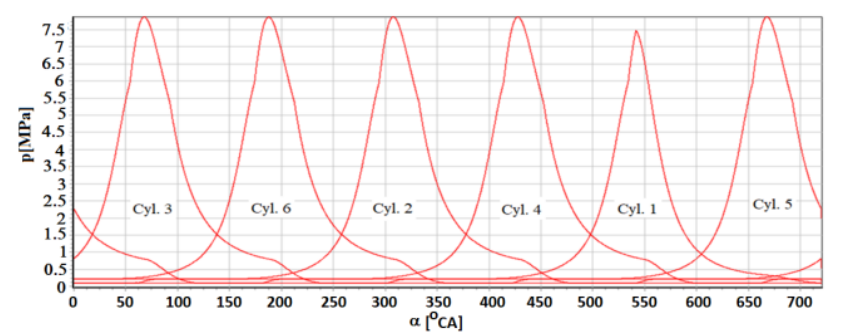

Fig. 1. The waveform of the indicated pressure in the engine cylinders as the function of the rotation angle of the crankshaft (cylinder no. 1 is supplied with an amount of fuel reduced by $80 \%$ )

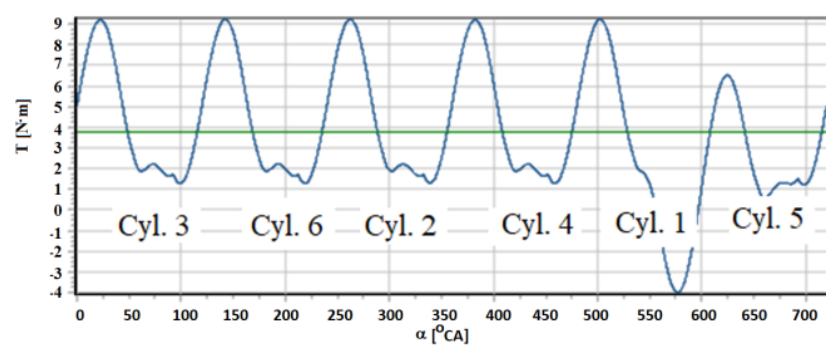

Fig. 2. The waveform of the torque of the engine crankshaft as a function of the rotation angle of the crankshaft (cylinder no. 1 is supplied with an amount of fuel reduced by $80 \%$ )

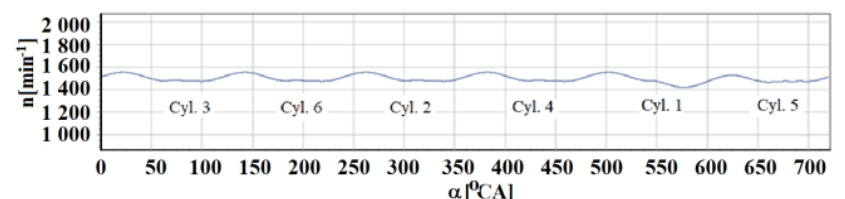

Fig. 3. The waveform of the rotational speed of the engine crankshaft as a function of the rotation angle of the crankshaft (cylinder no. 1 is supplied with an amount of fuel reduced by $80 \%$ )

\section{Program of the conduct of the research}

Work on the development of a new method of technical condition evaluation of a marine auxiliary diesel engine were preceded by the development of a research program $[5,7,16,19]$. Usually such programs are presented in a form of an algorithm (Fig. 4). It includes all main stages of the conducted research. It has been decided that the research problem presented in this article will be solved [16] in two basic stages. The first stage covers the development of models of a diesel engine, i.e. physical and mathematical models accompanied by a computer program (to solve equations of the mathematical model). This stage ends with an evaluation of the adequacy of the mathematical model, carried out on the basis of the model and empirical tests. The second stage begins once the mathematical model of the engine has been found adequate. This stage includes extension of the developed model of the engine with a model of a synchronous type generator. This stage ends with the evaluation of adequacy of the mathematical model of an diesel-electric generator set based both upon the model and empirical examinations.

Division into two stages applied in our research is a result of the restricted possibilities we have had in con- ducing the research in case of auxiliary engines (representing restricted diagnostic susceptibility). Evaluation of adequacy of a model based upon the empirical tests would be extremely complex, if impossible at all. Therefore decision has been made to evaluate adequacy of the engine model (first stage) by applying empirical research to be conducted on an engine of a high diagnostic susceptibility (a laboratory test engine SULZER, type 6AL20/24). At the second stage it has been decided that a comparative analysis of measures describing the waveforms of the phase-to-phase voltages of the generator will be sufficient for the evaluation of adequacy of a model of the diesel-electric generator set (both for model and empirical examinations) [16].

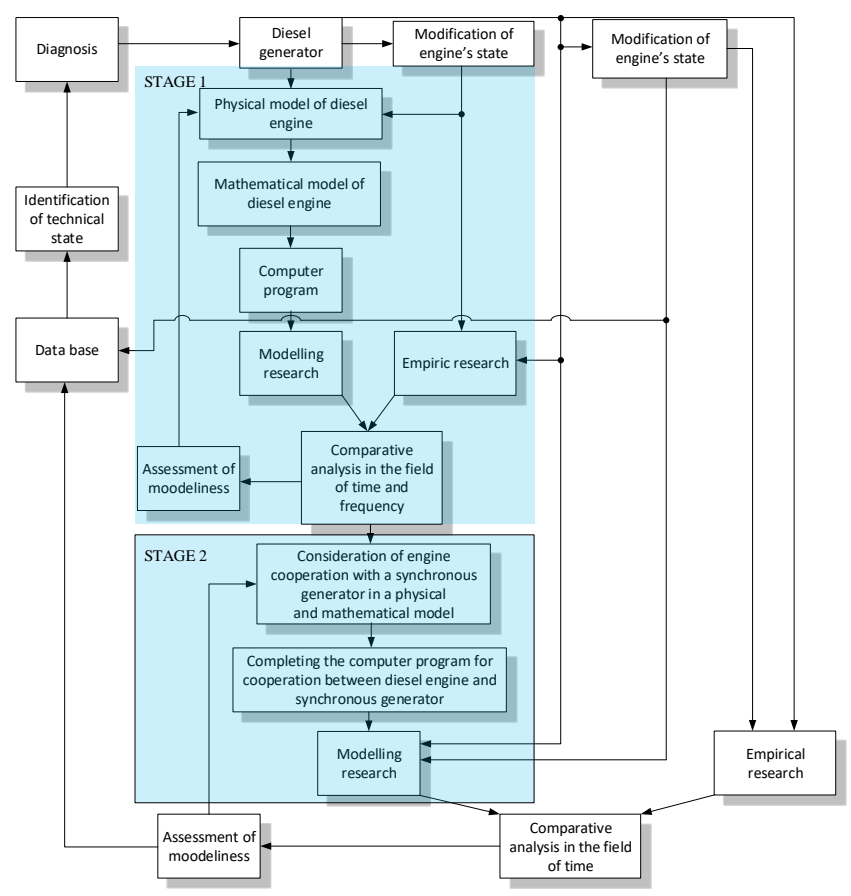

Fig. 4. Program of the research

\section{Mathematical model}

Following the program of the research presented in Fig. 4 (stage one) both physical model [17], and mathematical model [18] accompanied by a computer program have been developed. The physical and mathematical models allowed to conduct model tests for practically any of the four-stroke marine diesel engine. Such model allows to conduct the research on an engine representing both full and partial technical operational fitness. Solution of the equations of the mathematical model results in getting the waveforms of the following parameters (as the function of time or rotation angle of the crankshaft):

- stroke path, velocity and acceleration of a piston,

- volume of the combustion chamber,

- pitch of the inlet and outlet valves,

- cross-section areas of the inlet and outlet valves,

- velocity of the flow of the medium through the inlet and outlet valves,

- flow rate of the medium mass into and out of the engine cylinders,

- pressure, temperature, and medium mass inside the cylinders, 
- gas induced force moment,

- crankshaft revolution speed.

In addition, the following operational parameters of the engine are calculated:

- air excess factor,

- power indicated for any particular cylinder of the engine,

- fuel mass flow,

- heat flow stream carried off outside (together with exhaust gas) and to the cooling water.

The mathematical model provides possibility to conduct research on the following conditions of partial technical fitness for use:

- change in the fuel rate supplied to each one cylinder of the engine,

- change in the cross-section for any inlet and outlet valves,

- change in the fuel injection advance angle for any cylinder,

- leakage in the piston-piston rings-cylinder system for any piston,

- change in the cross-section area of the openings in the discharge jet of any injector,

- change in supercharging pressure,

- change in the resistance of the exhaust outlet duct.

When modelling the defects of the engine, consideration was directed to the impact of the speed governor operation that modifies fuel rates supplied to any of the cylinders of the engine in order to maintain the revolution rate of the crankshaft constant (i.e. constant power indicated of the engine).

\section{The plan of the experiment}

According to the adopted research methodology, the experiment was conducted following three main stages: the planning of the experiment, its performance followed by evaluation of the obtained results [13]. In case of evaluating of adequacy of the mathematical model it was decided to conduct both empirical and model research according to the same plan. According to the research realization program (Fig. 4) the analysis of the results allows to conclude whether the proposed model is adequate to the degree assumed by the researcher. In case of an insufficient adequacy of the model in relation to the adopted research program decision is made to return to the modelling stage by changing the level of the applied simplifications. The plan of the experiment was developed for an engine operated in a static condition (a static plan was adopted) [13]. It was decided to adopt a determined plan (the values of the input parameters were selected at the very early stage of the plan development on the basis of a logical analysis of the structure and operational conditions of the object of the research. In our research it was assumed that the input parameters were the crankshaft revolution speed and torque. These parameters were converted into the indicated engine power. The tests were conducted following a selective plan (limited number of input parameters that allow possibility to determine the functions of the object under the test).

Empirical tests were carried out on the SULZER engine type 6AL20/24, installed on a laboratory work-stand at the
Polish Naval Academy. It is a four-stroke Diesel engine, six-cylinder, in line type, supercharged by means of a turbocharger. The reason for such selection was its high diagnostic susceptibility (engine provided with indicator valves) and a unique system for measuring and recording its power parameters (the latter developed at the Polish Naval Academy). The applied measuring system allows measurement and registration of a number of engine operating parameters. The following were used in the research:

- Indicated pressure measured with the MA 2005 instrument (KISTLER 7613B transmitter) with a measuring range from 0 to $25 \mathrm{MPa}$ and a resolution of 12 bit. The measurement error did not exceed $0.5 \%$.

- Hourly fuel consumption measured by a weighing system, the measurement error did not exceed $1 \%$.

- Excess air ratio meeting the requirements of MARPOL Annex VI convention.

- Indicated power was calculated on indicated pressure.

It was decided that the tests would be carried out for the following engine crankshaft rotational speeds: 400, 500, 600, 700 and $750 \mathrm{rpm}$. However, the engine's torque load will be as follows: idle, 2.2, 2.96, 3.7, 4.2 and $5.12 \mathrm{kNm}$. The scope of measurements was limited by characteristics of marine diesel engine cooperated with fixed propeller.

In case of tests conducted on a defective engine (one cylinder out of service) it was decided to restrict the number of measuring points (in relation to the fully fit engine). This results from the fact that in case of the defective engine it was impossible to apply the load torque within the entire range of its propeller propulsion characteristics. Such a conclusion results from the initial empirical tests and tests carried on the model.

\section{Measures of adequacy of the mathematical model}

Based upon an analysis of the parameters resulting from the solution of equations of the mathematical model and from empirical tests (initial tests) it was decided that the measures of adequacy will be the following engine operational parameters:

- air excess factor (it was assumed that its relative value should not differ by more than by $20 \%$ ),

- fuel mass stream (relative difference should not exceed $10 \%$ ),

- maximum rate of the indicated pressure (not more than by $5 \%$ ).

In addition, measure "K" was developed for the needs of evaluating adequacy of the model that characterizes, in an objective manner, differences between the indicated pressure curves being a function of the rotation angle of the crankshaft.

The value ranges of adequacy measures were selected on the basis of preliminary studies (model and empirical). These studies concerned the assessment of the impact of modeled engine damage on the shape of the crankshaft angular velocity as a function of the crankshaft angle [16]. It has been observed that the introduced damages (concerning all engine cylinders) acceptable for the researcher (allowing for unambiguous identification of damages based on 
the developed method) cause changes in the adequacy of examined measures in the range.

In case of empirical tests it was observed that the indicated pressure curves as a function of the rotation angle of the crankshaft fundamentally differ from any particular cylinder of one engine (difference between the maximum rates of the indicated pressure for a particular cylinder of the engine differ from one another even by 10\%). Therefore for the needs of developing measure " $\mathrm{K}$ " it was decided to establish an averaged curve of the indicated pressure (as the function of revolution angle of the crankshaft) for all cylinders of the said engine (this was found to be representative for the engine). The curves of the indicated pressure as the function of the revolution angle of the engine crankshaft (an averaged curve) and the curve obtained as a result of solving the equations of the mathematical model are shown in the Graph 5. Then, the curve of the surface area under the curves of the indicated pressure was determined as the functions of the crankshaft revolution angle based upon the equation (1), what is shown in Fig. 6:

$$
\begin{gathered}
\mathrm{S}_{1}(\alpha)=\int_{0}^{720} \mathrm{p}_{\text {SCmodel }}(\alpha) \mathrm{d} \alpha \\
\text { and } \quad \mathrm{S}_{2}(\alpha)=\int_{0}^{720} \mathrm{p}_{\text {SCmeasure }}(\alpha) \mathrm{d} \alpha
\end{gathered}
$$

where: $S_{1}(\alpha)$ - Surface area grow under the averaged curve of the indicated pressure as the function of crankshaft revolution angle for the real object, $S_{2}(\alpha)$ - Surface area under the curve of the indicated pressure as the function of the crankshaft revolution angle for the model.

The value of the "S" parameter is an increment as a function of the crankshaft rotation angle (in Fig. 5). This approach specify its value for each crankshaft's angle of rotation (it is the so-called integral course). The value of the adequacy measure " $\mathrm{K}$ " was calculated using the following formula:

$$
\mathrm{K}(\alpha)=1-\frac{\mathrm{s}_{1}(\alpha)}{\mathrm{S}_{2}(\alpha)}
$$

The "K" parameter calculated on the basis of the " $\mathrm{S}_{1}$ " and " $\mathrm{S}_{2}$ " integral waveforms also it is a function of the engine crankshaft rotation. Therefore, its value changes during the engine's operating cycle. Presenting this parameter as a function of the angle of rotation allows for comparison of the shape of the indicated pressure waveforms obtained as a result of model and empirical tests for each angle of rotation of the crankshaft. The curve for parameter "K" is shown in the Fig. 7.

It was found that high values of the " $\mathrm{K}$ " measure in the range from $0^{\circ} \mathrm{CA}$ up to the angle of the injector opening are not significant from the point of view of the research. This is due to the fact that in this range the value of the indicated pressure is low, due to which its impact on the torque values (angular velocity fluctuations) is small. The high values of the " $K$ " measure in this respect are a consequence of the method used to calculate the "K" parameter as the relative value of the difference between " $S_{1}$ " and " $\mathrm{S}_{2}$ ". For low values of indicated pressure, even a small discrepancy (quantity) causes significant values of the "K" parameter. From the point of view of the conducted re- search, it is important to "similarity" waveforms in terms of the crankshaft rotation angle corresponding to the highest value of indicated pressure. The range from the injector opening angle to the outlet valve opening angle was considered to be the most important. The values of the injected pressure are then the largest and therefore have the greatest impact on the torque values.

It was assumed that the reference level will be the rate of the "K" index calculated for the angle of the injection starting point. The deviations from such rate by more than 10 prove an insufficient adequacy of the model.

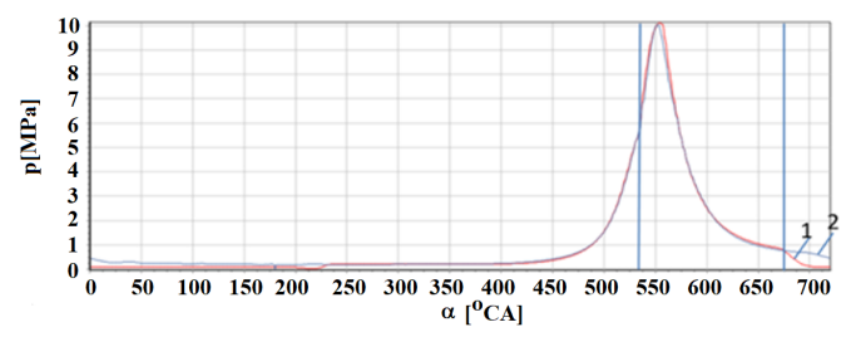

Fig. 5. Curves of the medium pressure: 1 - obtained from the model, 2 - measured as the function of the crankshaft revolution angle

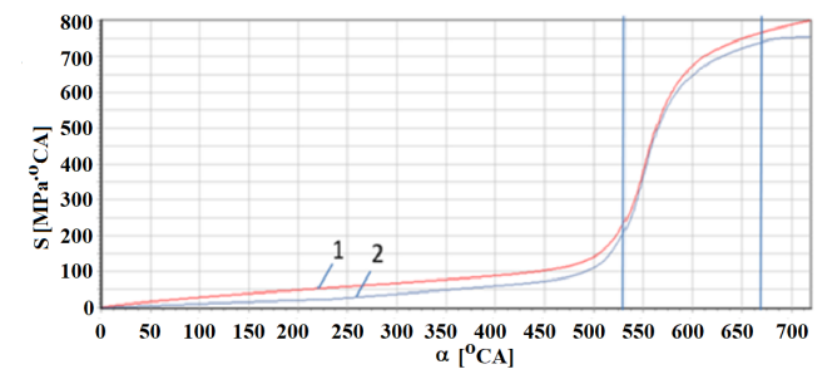

Fig. 6. Integral curves of the medium pressure: 1 - obtained from the model, 2 - measured as the function of the crankshaft revolution angle

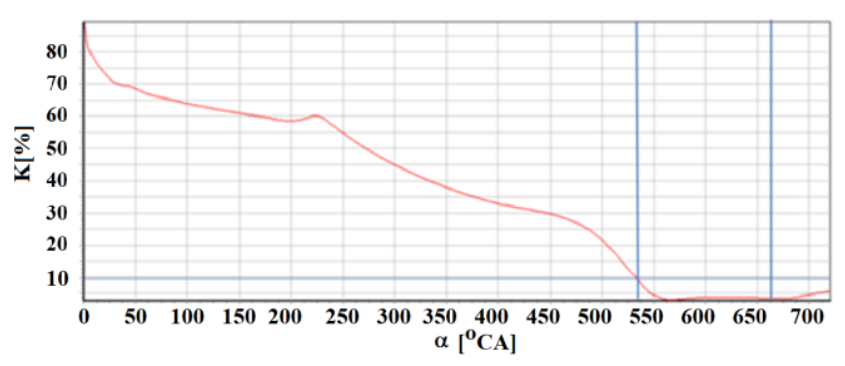

Fig. 7. The curve of the "K" parameter as the function of the crankshaft revolution angle

\section{Analysis of the test results}

Following the presented research plan for the engine fit for use empirical and model tests were carried out. Their results were presented in publications of the authors $[7,16$, 17]. The adequacy measure values calculated for both the fit for use and defective engine are shown in Tables 1 and 2. The yellow colour indicates measures exceeding the assumed values.

In the case of tests conducted for engines in a state of partial technical fitness, the use of the "K" adequacy measure was resigned. This is due to the method used to determine the indicated pressure course for the real engine. It was assumed in the research that the indicated pressure 
course used to calculate the "S" parameter is averaged for all engine cylinders (synchronous averaging). This approach was specified by the fact that there were significant discrepancies in the indicated pressure course for individual engine cylinders (the combustion pressure difference between engine cylinders sometimes reaches up to $10 \%$ ). These discrepancies result from:

- the adjustment of the engine pump for its nominal operating conditions,

- simultaneous measurement of the indicated pressure on all engine cylinders,

- wave phenomena occurring in the indicator valve channels.

In the case of a damaged engine (cylinder out of operation), calculating the average indicated pressure course would lead to significant errors.

In case of tests carried out on the damaged engine the number of adequacy measures has been reduced by measure "K". This results from the fact that when developing the probability measure for the indicated pressure waveform an averaged rate of indicated pressure has been applied and that has been obtained from all cylinders of the marine engine. In case of the damaged engine application of such measure is not justified [16].

Table 1 . The adequacy measure rates adopted for the engine of full technical state

\begin{tabular}{|c|c|c|c|c|c|c|c|}
\hline \multirow{6}{*}{ 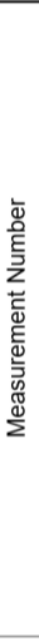 } & 5.12 & $\begin{array}{c}p_{\mathrm{SCmaxx}}[\%] \\
G_{\mathrm{er}}[\%] \\
\lambda_{\mathrm{r}}[\%] \\
K[-]\end{array}$ & & & & & $\begin{array}{l}2.19 \\
6.05 \\
0.00 \\
2.17\end{array}$ \\
\hline & 4.2 & $\begin{array}{c}p_{\mathrm{SCmaxx}}[\%] \\
G_{\mathrm{er}}[\%] \\
\lambda_{\mathrm{r}}[\%] \\
K[-]\end{array}$ & & & & $\begin{array}{l}0.20 \\
8.08 \\
2.06 \\
4.64\end{array}$ & $\begin{array}{l}0.19 \\
7.66 \\
3.09 \\
3.80\end{array}$ \\
\hline & 3.7 & $\begin{array}{c}p_{\mathrm{SCmaxr}}[\%] \\
G_{\mathrm{er}}[\%] \\
\lambda_{\mathrm{r}}[\%] \\
K[-]\end{array}$ & & & $\begin{array}{l}0.72 \\
4.96 \\
7.69 \\
8.16 \\
\end{array}$ & $\begin{array}{l}0.54 \\
3.32 \\
2.70 \\
4.76\end{array}$ & $\begin{array}{l}4.13 \\
8.04 \\
4.83 \\
5.02 \\
\end{array}$ \\
\hline & 2.96 & $\begin{array}{c}p_{\mathrm{SCmaxx}}[\%] \\
G_{\mathrm{er}}[\%] \\
\lambda_{\mathrm{r}}[\%] \\
K[-]\end{array}$ & & $\begin{array}{l}4.32 \\
0.29 \\
0.55 \\
4.14 \\
\end{array}$ & $\begin{array}{l}4.14 \\
1.99 \\
8.00 \\
8.90\end{array}$ & $\begin{array}{l}2.07 \\
1.34 \\
6.34 \\
8.19 \\
\end{array}$ & $\begin{array}{l}2.07 \\
4.18 \\
2.44 \\
4.27\end{array}$ \\
\hline & 2.2 & $\begin{array}{c}p_{\mathrm{SCmaxr}}[\%] \\
G_{\mathrm{er}}[\%] \\
\lambda_{\mathrm{r}}[\%] \\
K[-] \\
{ }^{2}[\%]\end{array}$ & $\begin{array}{l}4.73 \\
3.76 \\
1.69 \\
5.10 \\
\end{array}$ & $\begin{array}{l}2.76 \\
4.12 \\
8.25 \\
5.43 \\
\end{array}$ & $\begin{array}{c}1.95 \\
8.77 \\
18.27 \\
5.54 \\
\end{array}$ & $\begin{array}{c}0.65 \\
60.6 \\
18.10 \\
3.51 \\
\end{array}$ & $\begin{array}{l}2.55 \\
2.96 \\
2.80 \\
3.27 \\
\end{array}$ \\
\hline & 0 & $\begin{array}{c}p_{\mathrm{SCmaxx}}[\%] \\
G_{\mathrm{er}}[\%] \\
\lambda_{\mathrm{r}}[\%] \\
K[-] \\
\end{array}$ & $\begin{array}{c}3.60 \\
113.00 \\
15.67 \\
3.40 \\
\end{array}$ & $\begin{array}{c}1.90 \\
30.00 \\
8.85 \\
5.95\end{array}$ & $\begin{array}{c}5.99 \\
10.01 \\
6.97 \\
5.47 \\
\end{array}$ & \begin{tabular}{c|}
7.38 \\
2.58 \\
11.74 \\
1.70 \\
\end{tabular} & $\begin{array}{l}0.98 \\
3.78 \\
3.08 \\
3.80 \\
\end{array}$ \\
\hline \multicolumn{3}{|c|}{$\frac{M_{O P}[\mathrm{kN} \cdot \mathrm{m}]}{n\left[\mathrm{~min}^{-1}\right]}$} & 400 & 500 & 600 & 700 & 750 \\
\hline
\end{tabular}

Table 2. The adequacy measure rates adopted for the engine of partial technical fitness for use

\begin{tabular}{|c|c|c|c|c|c|c|c|}
\hline \multirow{4}{*}{ 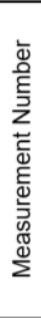 } & 3.7 & $\begin{array}{c}p_{\text {SCmaxr }}[\%] \\
G_{\text {er }}[\%] \\
\lambda_{\mathrm{r}}[\%]\end{array}$ & & & $\begin{array}{l}4.06 \\
4.05 \\
4.94\end{array}$ & $\begin{array}{l}3.85 \\
0.81 \\
7.80\end{array}$ & $\begin{array}{l}4.95 \\
0.77 \\
3.07\end{array}$ \\
\hline & 2.96 & $\begin{array}{c}p_{\mathrm{SCmax}}[\%] \\
G_{\mathrm{er}}[\%] \\
\lambda_{\mathrm{r}}[\%]\end{array}$ & & $\begin{array}{l}0.36 \\
8.74 \\
7.41\end{array}$ & $\begin{array}{l}3.89 \\
2.37 \\
5.77\end{array}$ & $\begin{array}{l}2.66 \\
1.07 \\
4.38\end{array}$ & $\begin{array}{l}4.39 \\
0.00 \\
0.63\end{array}$ \\
\hline & 2.2 & $\begin{array}{c}p_{\text {SCmaxx }}[\%] \\
G_{\text {er }}[\%] \\
\lambda_{\mathrm{r}}[\%]\end{array}$ & $\begin{array}{l}3.86 \\
4.55 \\
1.41\end{array}$ & $\begin{array}{l}4.32 \\
0.63 \\
7.69\end{array}$ & $\begin{array}{l}0.12 \\
1.68 \\
9.94\end{array}$ & $\begin{array}{l}2.85 \\
0.97 \\
8.85\end{array}$ & $\begin{array}{l}4.64 \\
3.07 \\
1.10\end{array}$ \\
\hline & 0 & $\begin{array}{c}p_{\mathrm{SCmaxr}}[\%] \\
G_{\mathrm{er}}[\%] \\
\lambda_{\mathrm{r}}[\%]\end{array}$ & $\begin{array}{c}5.50 \\
106.25 \\
41.18\end{array}$ & $\begin{array}{c}0.95 \\
14.93 \\
11.87\end{array}$ & $\begin{array}{c}8.67 \\
20.81 \\
3.28\end{array}$ & $\begin{array}{l}1.43 \\
3.13 \\
9.57\end{array}$ & $\begin{array}{l}0.89 \\
2.30 \\
6.99\end{array}$ \\
\hline \multicolumn{3}{|c|}{$M_{O P}[\mathrm{kN} \cdot \mathrm{m}]$} & 400 & 500 & 600 & 700 & 750 \\
\hline
\end{tabular}

Part of the measure values in case of both the entirely fit for use engine and defective engine exceeds the assumed values (measures marked in yellow in Tables 1 and 2). This proves the inadequacy of the model within the range of operation of the engine without the torque load. Despite the fact that the values of adequacy measures were exceeded it has been found that the developed model is adequate both in quantitative and qualitative terms within the limited range of loads. Decision was made that in case of the research described in this article the adequacy of the mathematical model of the engine is sufficient to pass on to the subsequent stage of the research program, i.e. to the modelling of a Diesel generator unit.

Operation of the engine without load, in case of Diesel generator units may only and exclusively take place at its starting up moment and continues until the operational parameters are reached that makes it possible to load the generator with the receivers. Moreover, the fact is to be taken into consideration that the average crankshaft revolutions of the engine driving the generator change within a very much narrow range (because of the necessity to generate electrical power of an assumed frequency of either $50 \mathrm{~Hz}$ or $60 \mathrm{~Hz}$ ). Also during the engine operation without the torque load numerous factors occur influencing the accuracy of measurements taken on the real object. The most essential include:

- lack of repeatability of the working cycle, particularly in case of low rates of the torque load,

- disturbances caused by the flow ducts of the indicator valves (occurrence of waving) [16]. These ducts are selected in such a manner to ensure the credible measurements of the indicated pressure for an engine operated at nominal revolutions with the nominal torque load,

- large length of the exhaust gas ducts causing the delays in recording the air excess factor,

- low accuracy of the measuring instrument used for measuring the fuel consumption rate (within the noload operation range of the engine). This instrument was selected in such a manner, to ensure the performance of measurements for the whole range of admissible engine crankshaft revolutions and for the torque loads,

- the marine piston type internal combustion engines represent a high unrepeatability of operational parameters of individual cylinders. This is caused by differences in the manufacturing of the fuel injection apparatus components (the fuel rate is selected for the nominal operating conditions of the engine), cylinder head liners and a number of other components [12].

\section{Conclusion}

Both the research on models and the empirical tests carried out have proven the fact that the developed mathematical model is adequate within a wide range of crankshaft revolutions and engine indicated power. Excess of the adopted adequacy measures occurs only and exclusively in case when the engine operates with no load. The high adequacy of the model has allowed to commence the second 
stage of the research program (Fig. 4). Moreover, based upon the analysis of the pressure curves shown in Fig. 5 (the model research and results obtained from the empirical tests) a conclusion may be drawn up that the application of the developed model may be decidedly wider than that used in our research. The high level of adequacy and versatility of the said model (possibility to model practically any fourstroke type Diesel engine) and also possibility to simulate selected conditions of a partial technical fitness for use make this model a useful tool for the development of other parametric methods for evaluation of technical fitness of the marine engines.

\section{Bibliography}

[1] BOGDANOWICZ, A., KNIAZIEWICZ, T., ZACHAREWICZ, M. The use of a mathematical model of marine diesel engine in a computer program. New Trends in Production Engineering. 2018, 1(1), 453-460. https://doi.org/10.2478/ntpe-2018-0056

[2] CAVINA, N., BUSINARO, A., ROJO, N. et al. Combustion and intake/exhaust systems diagnosis based on acoustic emissions of a GDI TC engine. Energy Procedia. 2016, 101, 677-684. https://doi.org/10.1016/j.egypro.2016.11.086

[3] CHIATTI, G., CHIAVOLA, O., RECCO, E. et al. Accelerometer measurement for MFB evaluation in multi-cylinder diesel engine. Energy. 2017, 133, 843-850. https://doi.org/10.1016/j.energy.2017.04.148

[4] CHŁOPEK, Z., PIASECZNY, L. Badania procesów szybkozmiennych zachodzących w silniku spalinowym. Zeszyty Naukowe AMW. 2004, 2(157), 5-28.

[5] CWALINA, A., KNIAZIEWICZ, T., ZACHAREWICZ, M. Problems of mathematical modelling of the marine diesel engine working cycle for the diagnostic purposes. Solid State Phenomena. 2015, 236, 212-219.

https://doi.org/10.4028/www.scientific.net/ssp.236.212

[6] KLUCZYK, M., GRZĄDZIELA, A. Vibration diagnostics of the naval propulsion systems. Scientific Journal of Polish Naval Academy. 2017, 1(208), 15-29.

https://doi.org/10.5604/0860889x.1237619

[7] KNIAZIEWICZ, T., ZACHAREWICZ, M. Ocena adekwatności modelu okrętowego tłokowego silnika spalinowego opracowanego na potrzeby badań diagnostycznych. Zeszyty Naukowe Akademii Morskiej w Gdyni. 2018, 108, 67-80.

[8] KORCZEWSKI, Z., ZACHAREWICZ, M. Alternative diagnostic method applied on marine diesel engines having limited monitoring susceptibility. Transaction of the Institute of Measurement and Control. SAGE. 2012, 34, 937-946. https://doi.org/10.1177/0142331211426170

[9] KORCZEWSKI, Z., ZACHAREWICZ M. The method of diagnosing warships engines with a limited capability of measuring indicating pressures based on the results of the gasdynamic processes in the turbocharging system. Polish Naval Academy. Gdynia 2008. Research project: 0T00B02129.

[10] ŁUTOWICZ, M. Reverse IIR filter as a tool for cylinder indicating channel patency impact correction on measured

Tomasz Kniaziewicz, DSc., DEng. - Faculty of Mechanical and Electrical Engineering, Polish Naval Academy.

e-mail:T.Kniaziewicz@amw.gdynia.pl cylinder pressure waveform. Journal of KONES. 2013, 20, 253-259.

[11] PAWLETKO, R., POLANOWSKI, S. Evaluation of current developments and trends in the diagnosis of marine diesel engines based on the indicator diagrams analysis. Journal of KONES Powertrain and Transport. 2014, 21(4), 389-396. https://doi.org/10.5604/12314005.1130492

[12] PIASECZNY, L. Technologia napraw okrętowych silników spalinowych. Wydawnictwo Morskie. Linkoping 1992.

[13] POLAŃSKI, Z. Planowanie doświadczeń w technice. PWN. Warszawa 1984.

[14] WITKOWSKI, K. The issue of the indicator diagram analysis for the purpose of diagnosis of marine diesel engines. Journal of KONES Powertrain and Transport. 2015, 22(2), 293-298. https://doi.org/10.5604/12314005.1165456

[15] ZACHAREWICZ, M. A method of diagnosing working spaces of a marine engine based on gas-dynamic parameters in the duct supplying the turbo-charger. Polish Naval Academy. Dissertation. 2009.

[16] ZACHAREWICZ, M. Possibilities of parametric evaluation of the technical condition of a marine combustion engine of a low diagnostic susceptibility. Polish Naval Academy. Gdynia 2019.

[17] ZACHAREWICZ, M., CWALINA, A. Research on energetic processes in a marine diesel engine driving a synchronous generator for diagnostic purposes. PART 1 - Physical model of the processes. Journal of POLISH CIMAC. 2013, 8(1), 97-104.

[18] ZACHAREWICZ, M., KNIAZIEWICZ, T. Research on energetic processes in a marine diesel engine driving a synchronous generator for diagnostic purposes. Part 2 mathematical model of the processes, Journal of POLISH CIMEEAC. 2016, 11(1), 199-209.

[19] ZACHAREWICZ, M., KNIAZIEWICZ, T., CWALINA, A. Assessment of technical condition of marine auxiliary diesel engine on the basis of electrical measurements of synchronous generator. Combustion Engines. 2015, 3(162), 170176.

[20] ŻÓŁTOWSKI, B., ŻÓŁTOWSKI, M. Vibration signals in mechanical engineering and construction. ITE-PIB. Radom 2015.

Marcin Zacharewicz, DSc. DEng. - Faculty of Mechanical and Electrical Engineering, Polish Naval Academy.

e-mail:M.Zacharewicz@amw.gdynia.pl

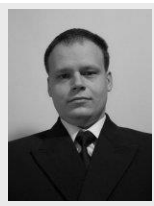

